\title{
Advanced Practice Registered Nurse - Led Transition of Care for Congestive Heart Failure Patients
}

\section{Kelli Camp, DNP, APRN, FNP-BC}

Professor, School of Nursing \& Healthcare Science, Arkansas State University, USA

\author{
Corresponding author \\ Kelli Camp, DNP, APRN, FNP-BC, Professor, School of Nursing \& \\ Healthcare Science, Arkansas State University, USA, Tel+: 870.508.6137; \\ E-Mail: kcamp@asumh.edu
}

Submitted: 11 May 2018; Accepted: 18 May 2018; Published: 30 May 2018

\begin{abstract}
Purpose: This scholarly project was to determine if an advanced practice registered nurse (APRN) - led transition of care (TOC) would positively influence the outcome of quality of life in congestive heart failure (CHF) patients. The purpose was to meet Medicare-mandated target goals in reducing readmission to $12 \%$. The project investigates the gap between the time of discharge and transition of care. The improvement plan objectives are threefold: to increase retention of self-care activities utilizing the teach-back method while monitoring emergency room (ER) utilization and measuring benchmark assessment. This project aligns with one of the Institute of Medicine [IOM] six dimensions of patient-centered care.
\end{abstract}

Findings: In the period of February 22 - March 22, 2018, ten subjects were enrolled in the project $(N=10)$. Even though chi square analysis revealed no significant difference $\left(x^{2}(1, N=10)=2.3746, p=.1233\right)$ in readmissions post intervention (See Appendix -T); APRN - led TOC demonstrated positive changes in teach back and reteach via leadership competences and clinical experience revealing overall improvement in trends.

Discussion: There were ten participants in the pilot study $(N=10)$. Out of these ten $C H F$ patients one was readmitted in the 30-day period of the study. All subjects were carefully followed and monitored. Field assessment benchmark revealed that at one week $100 \%$ of all patients were retaining $90 \%$ or more of the self-care activities and maintaining appropriate priority tasks. There was no ER utilization and patients in the "yellow" zone knew what to do with a three-pound weight gain.

Keywords: Aging, Readmission Rates, Congestive Heart Failure, Drug Adherence, Transitional Care and Follow Up

\section{Introduction}

As the Centers for Medicare and Medicaid (CMS) shift to the use of Accountable Care Organizations (ACOs) reimbursement is expected to decrease and be based off outcomes versus current practices [1]. This shift has hospitals concerned when it comes to chronic diseases such as CHF and readmission penalties.

Current modalities and practices at MR include two dedicated discharge registered nurses (RNs), morning huddles, and implementation of social services. The effect on reducing readmissions for CHF patients have been minimal. See trends on Appendix - A. The problem statement is defined as the movement from one health care setting to the medical home and an untimely follow up puts CHF patients in a dangerous place for complications [2]. Lack of continuity coordination leaves the patient vulnerable at discharge and can lead to inadequate directions on whom to contact if symptoms deteriorate, and in effective symptom management [3,4]. Data at this facility reveals that a small percentage of patients receive long term care (LTC) or skilled nursing care. A gap lies in the population that do not have access to supervised care post discharge. This population is approximately $30 \%$ of all CHF patients at MR (S. Rodden, personal communication, December 8, 2016).

The literature shows the highest readmission rates occur during the five to seven days post-discharge [5]. Current traditional transitional of care follows up is two weeks. The gap between follow-up at two weeks and point of highest readmission rates. See Appendix A. This practice is not only costly for the hospital, it is not patient-centered. Medicare revealed 50\% of patients who were readmitted in 30 days had minimal to no access to healthcare [1].

The break in transition of care leads to frequent visits to the emergency room [3]. This quality improvement (QI) project will seek to improve CHF patients' retention of discharge instructions, implement the APRN to call and visit in the home to attempt to lower the readmission rates. 
Purpose of the Project

The purpose of this project was to plan, implement, and evaluate a small pilot study. The method was to implement a teach-back session on each participant at discharge and again at the home visit via the APRN. The evaluation would collect the pass and fail rate of the teach-back tool. The evaluation aligned with objectives and outcomes in the project design section and were monitored closely for improvement.

\section{Purpose, Objectives, and Outcomes}

The purpose was to reduce preventable readmissions and lower costs by utilizing an APRN - led transition of care. The outcome measure was the number of readmissions within those 30 days. The outcome expectation was a $12 \%$ decrease in the number of readmissions in one month. This goal is recognized as Medicare's and MR's state mandated benchmark (S. Rodden, personal communication, Dec. 8, 2016). This data was collected and analyzed at MR. The outcome was based on absolute percentages, raw data and a chi square analysis. This data was compared with the pre-data for significance.

One objective was for the patient to verbalize his/her discharge expectations utilizing the teach-back method. The outcome expectation was a $90 \%$ pass rate. The outcome is based on the percentage of questions the patients answer correctly. The outcome is that patients would gain a better understanding at hospital discharge, including self-care expectations.

Data was obtained on the ability to recall educational information during hospitalization and a one-week home visit with the same data collection [6]. Metrics were developed to self-report or interview participants of enhanced learning at discharge and at home visit. This metric measured how many questions they confidently answered correctly. Reteaching was also part of this projects outcome.

The next objective was the benchmark assessment. The data obtained was analyzed and compiled to aid in an observation of how the teach back method influenced self-care activities and ifthe patients had to utilize the ER. The outcome was analyzed for frequencies and presented in tables. The expected outcome was less than five percent utilization of the ER.

Another objective related to the fieldwork is the assessment. This assessment piece was to use as a benchmark that the APRN would determine patient's base weight (at discharge and at one week follow up), review self-care activities (i.e., weighing daily), and instruct them on how to use the telemedicine and measurement tools (i.e. scale). Additional instructions include what to do when their weight increases more than three pounds, and how to know when it is in the "yellow zone" or caution. This piece was taught using the stoplight teach-back assessment tool. The outcome expectation was that the patient would notify the HHA/CCP or primary healthcare provider of finding by self-report. The outcome is that patient will seek aid with healthcare professional for additional medication adjustment versus preceding to the ER.

\section{The Subjects}

The inclusion criteria included subjects between the ages of 65-90 years of age. A patient discharged from MR after being admitted with primary or secondary diagnosis CHF. The participants were chosen on a voluntary basis. The exclusion criteria included any patient requiring structural repair of the disease process. Structural repair means coronary bypass, aortic valve replacement, or mitral valve repair. Patients that reside in a skilled nursing facility (SNF), hospice, and long-term care facility and home health with another agency will be out of the scope of this project. Sampling would have consisted of a convenience while both are based on availability [7].

\section{The Setting}

The population of Mountain Regional (MR) and surrounding county is approximately 41,000 people (Census, 2016). MR is a not-forprofit institution and rated 14.2 out of 100 for the cardiology and heart surgery scorecard [8]. MR is a 160-bed medical-surgical hospital in a rural setting. This facility has a coronary care unit, level 1 trauma ER, and cardiovascular intensive care unit. This geographical area is rural with the closest tertiary facility being two and a half hours away.

\section{Tool}

The instrument was used in the form of a stoplight CHF teach-back tool [9]. This four-question tool were used to measure the patient's retention. See Appendix - E. The use of tables and flow sheets will record observations.

\section{Operational Definitions}

The tool is evidenced-based and has been validated by the Agency for Healthcare for Research \& Quality (AHRQ) and was utilized to measure retention (2017) [9]. This tool uses zones for management. It consists of four questions. The questions are broken into three sections: green zone, yellow zone, and red zone. Each zone has symptoms associated with it. Question 1) what does it mean to have your symptoms under control and in the green zone? Question 2) what symptoms suggest you are in the yellow zone and need to call your primary care physician for medication adjustments? Question 3 ) what symptoms indicate you are in the red zone and need to be evaluated right way? Question 4) what self-care activities do you perform daily as prescribed by the physician and practitioners? The numerator is the number of questions the patients get correct, and the denominator is the number of questions (Question 1) 5/5; (Question 2) 7/7; (Question 3) 6/6 \& (Question 4) 4/4 for a total of 22 . One question incorrect is a score of $95 \%$ and two incorrect is a score of $90 \%$.

\section{Intervention}

The intervention of implementing an education tool and an APRNled transition of care utilizing the community paramedic program (CPP) or home health agency (HHA) instead of a mentor as a blended concept of the CTI and the Naylor's modified model.

The role of the DNP student was to create a relaxed, safe, and trusting environment. The stoplight teach-back tool allowed the APRN to compare retention at the time of discharge and at the oneweek visit. The behavior was measured for competency-based on a nonexperimental, flexible, and triangulation approach for increased validity. Steps in this process were as follows (see Appendix R):

1. The director of home health services coordinator notified the APRN about anticipated discharges that qualify for inclusion to the project. The APRN met the coordinator at the institution for briefing. The project was discussed with the participant and consent was obtained.

2. The discharge nurse notified the DNP student at the time of discharge. The APRN utilized the stoplight teach-back tool 
and monitored the participants by voice, body language, and explanation of expectations. See Appendix-E.

3. The DNP student asked the participant four questions from the tool to see if he/she retained the discharge instructions. See Appendix-E.

4. Twenty-four hours after discharge, the paramedic or home health assistant (HHA) called the subject to assure the patient has obtained his/her medications and verifies a one-week home visit appointment. If the participant did not acquire their medications, the CPP and HHA intervened to assure that they acquired their medications. Several pharmacies in the area were identified to assist and deliver medications.

5. After one week, the subject had a home visit. Both professionals, the APRN and the paramedic/HHA, conducted the home visit for observation and data obtainment. A questionnaire, checklist, stoplight teach-back tool, and flow sheet was available to measure the home visit progress.

6. The participant's weight at discharge and at home visit was measured.

7. The follow up appointment with the primary care provider is secured and education is given. The participants are monitored for 30 days to determine causes for readmission.

\section{Analysis}

This project of program development and quality improvement utilizes plan, do, study and act (PDSA) cycle for systematic tests of improvement [10]. This project investigated qualitative and quantitative research questions and data. A systematic, retroactive chart review was performed on the pilot group of ten patients. This project utilized tools to assess retention, efficiency, and accuracy (Moran, 2012, p. 131). Critical literature review and appraisal of other researchers' works provided information to promote a strong study design and limit bias [11]. The IHI Evidence-Based Model using the PDSA model is an organizational quality improvement model with fundamental distinction and techniques to execute changes [12]. The IHI quality improvement has three questions: 1) what are we trying to accomplish? 2) How will we recognize a change as an improvement? And 3) what changes will result in an improvement? With the PDSA cycle, improvements can be achieved with this three -dimensional framework [13]. The way to a quality improvement project is to accomplish this task by studying the intervention and program improvement with the small incremental changes utilizing the systematic approach. PDSA is an ongoing process that the organization becomes more efficient as the team adopts the PDSA in their planning [14]. The purpose was to evaluate if such tools and intervention were in place, the overall goal or purpose is to lower readmissions for CHF patients to ultimately lower hospital costs and improve patients' access to care during their most vulnerable time. Additionally, another primary focus and objective is to evaluate known the causes for readmission such as increased weight, non-adherence to medication, and/or the absence of follow up.

\section{Results}

In the period of Feb. 22 - March 22, 2018, there were 51 discharges with $\mathrm{CHF}$ and were recorded for the hospital service through the CDI nurses and inclusion criteria. Ten were enrolled into the project $(\mathrm{N}=10)$. The exclusion of 41 participants included that eight patients were transferred to SNF, two to hospice, four refusals, one long term care, five out of town during the planned follow up period, 18 already enrolled into MR home health services and three to different home health agencies. The sample population were seven new home health enrollees and three to community paramedic program (CPP).

Frequencies revealed $40 \%$ female and $60 \%$ male. The mean age is 76.9 (oldest 90 years of age, and youngest is 63 years of age).

To measure the success of the interventions and the achievement of the first goal, pre-data was compared topost intervention data. The goal was a $12 \%$ reduction. Findings are consistent with a $10 \%$ reduction as found on Table 1 .

Table 1: Readmission rates

\begin{tabular}{|c|c|c|}
\hline Subjects & In 7 days & In 30 days \\
\hline 1 & 0 & 1 \\
\hline 2 & 0 & 0 \\
\hline 3 & 0 & 0 \\
\hline 4 & 0 & 0 \\
\hline 5 & 0 & 0 \\
\hline 6 & 0 & 0 \\
\hline 7 & 0 & 0 \\
\hline 8 & 0 & 0 \\
\hline 9 & 0 & 0 \\
\hline 10 & 0 & $1(10 \%)$ \\
\hline Total & 0 & \\
\hline
\end{tabular}

A chi square analysis using the SAS program was performed revealing no statistical difference in readmissions from the preinterventional (control group) to the post interventional group (test group). $(\mathrm{x} 2(1, \mathrm{~N}=10)=2.3746, \mathrm{p}=.1233)$.

The next objective of the QI project was focused on patients meeting self-care activities utilizing the teach back method. See Appendix E. For this project the success rate will be set at pass rate of $90 \%$ of participants will achieve. These measurement intervals will occur at the discharge and one-week home visit. Only half (50\%) or five passed the teach-back tool at discharge (three females and two males). The at home pass rate was $100 \%$ as found on Table 2 .

Table 2: Scores

\begin{tabular}{|c|c|c|}
\hline Subjects & Discharge & Home Test \\
\hline 1 & $70 \%$ & Refused \\
\hline 2 & $80 \%$ & $90 \%$ \\
\hline 3 & $90 \%$ & Refused \\
\hline 4 & $90 \%$ & $100 \%$ \\
\hline 5 & Refused & Refused \\
\hline 6 & $80 \%$ & $90 \%$ \\
\hline 7 & $90 \%$ & $90 \%$ \\
\hline 8 & $100 \%$ & $95 \%$ \\
\hline 9 & $68 \%$ & $90 \%$ \\
\hline 10 & $95 \%$ & Refused \\
\hline Total Percentage & $50 \%$ & $100 \%$ \\
\hline
\end{tabular}


Another objective of the QI project was a part of a field benchmark assessment. The data obtained was analyzed and compiled to aid in an observation of self-care activities and if patients had to utilize the ER. For this project the success rate was set at percentage of zero percent. The outcome was analyzed for frequencies and presented in tables and a narrative self-report. This goal was meet at zero percent. These measurement intervals were recorded at a 30-day interval as found on Table 3 .

Table 3: ER Utilization

\begin{tabular}{|c|c|}
\hline Subject & ER Utilization \\
\hline 1 & None \\
\hline 2 & None \\
\hline 3 & None \\
\hline 4 & None \\
\hline 5 & None \\
\hline 6 & None \\
\hline 7 & None \\
\hline 8 & None \\
\hline 9 & None \\
\hline 10 & None \\
\hline Total ER Utilization & $0 \%$ \\
\hline
\end{tabular}

Another field benchmark assessment focused on weight gain. The goal was less than three pounds. As part of the teach-back, the "caution zone" or "yellow zone" or knowing when to call the primary healthcare provider or cardiologist was if daily weight gain was greater than three pounds with or without symptomology. These measurement intervals were recorded at the home assessment as found on Table 4.

Table 4: Weight Assessment

\begin{tabular}{|c|c|c|c|}
\hline Subject & $\begin{array}{c}\text { Discharge } \\
\text { Weight }\end{array}$ & $\begin{array}{c}\text { Follow up } \\
\text { Weight }\end{array}$ & $\begin{array}{c}\text { 3lb weight }> \\
\text { Yes or No }\end{array}$ \\
\hline 1 & 160 & Refused & No \\
\hline 2 & 185 & 189 & Yes \\
\hline 3 & 156 & Refused & No \\
\hline 4 & 149 & 152 & Yes \\
\hline 5 & 172 & Refused & No \\
\hline 6 & 156 & 152 & No \\
\hline 7 & 190 & 190 & No \\
\hline 8 & 169 & 170 & No \\
\hline 9 & 200 & 190 & No \\
\hline 10 & 202 & Refused & No \\
\hline Total \% gain > 3lbs & & & $20 \%$ \\
\hline
\end{tabular}

\section{Significance}

A single facility quality improvement plan indicates that the APRNled TOC did not statistically impact the readmission rate per results of the chi square. When comparing month to month absolute percentages there was a ten percent readmission versus $16 \%$ for all CHF cases during the months project and an overall reduction when compared to $24.5 \%$ on the quality improvement reports. See Appendix - A \& Table -1 . The goal was a $12 \%$ reduction therefore the goal was meet.

The teach-back method did aid in retention and knowledge of selfcare as evidenced by the improved test scores at the home. These test scores went from $50 \%$ to $100 \%$ improvement. This objective was meet at $100 \%$, the overall improvement reveals a positive trend and by self-report aided in patients "knowing what to do".

Another QI projective objective was the field benchmark assessment results. The benchmark assessment revealed that the patients developed improved self-care activities with no ER utilization. This outcome was met.

Patients that developed a weight gain of three pounds with or without associated progressive symptoms were directed by the APRN to call the primary care provider as part of the teach-back tool. This goal was meet with $20 \%$ of the patients responding to directions. Two patients had a three-pound weight gain and called the primary care providers for further treatment. One patient proceeded to his family doctor that day with intervention of additional diuretic for three days; the other patient was instructed through to take an extra dose of Furosemide that day. More importantly, both patients expressed increase knowledge of what steps to take when associated with weight gain in the "yellow zone" with or without symptoms. Selfreport of the patients being more cognizant of their "caution zone" symptomatology and were versed on when to contact their home care agency or provider for further instruction [15-54].

\section{Limitations}

The time constraint was the biggest limitation. This project needed time to follow the participants for a minimum of 60 days. The data was based on 30 days. The second limitation was the sample size. The sample size was so small that it is very difficult to determine a notable change. However, this a pilot study could begin a conversation or consideration for a bigger study in the future.

\section{Acknowledgments}

This project was quite a journey. It began with a professor, Dr. Barta; encouraging the DNP student to further her education. Dr. McNeill, commenting on what a great capstone idea this project could be. Dr. Stewart that encouraged the student to make it APRN led. The capstone chair; Dr. Kippenbrock; that paved the way to the completion. The capstone committee; Dr. Kippenbrock, Dr. McNeill \& Dr. Emory; with all the constant editing, direction and final approval. The agency mentor, JoAnne Dean; provided excellent advice and planning. Champion, Dr. Camp; provided editing, knowledge in the subject and emotional support. The math department professor, Matt Franklin; at Arkansas State University (ASUMH) provided aid in statistical analysis. The English professor at ASUMH, Jessica Sisco and the University of Arkansas writing center professionals; aided the project above and beyond during the revision process.

\section{References}

1. Feigle C (2011) Skepticism greets Medicare accountable care organization $[\mathrm{ACO}]$ shared savings program. American Medical Association News 54.

2. Naylor MD, Brooten DA, Campbell R L, Maislin G, McCauley KM,et al. (2004) Transitional care of older adults hospitalized with heart failure: A randomized controlled trial. Journal of the American Geriatrics Society 52: 375-384. 
3. Coleman EA, Chalmers S (2006) The care transitions intervention: Results of a randomized controlled trial. Archives of Internal Medicine 1822-1828.

4. Snow V, Beck D, Budnitz T, Miller DC, Potter J, et al.(2009) Transitions of care consensus policy statement American College of Physicians-Society of General Internal MedicineSociety of Hospital. Society of Academic Emergency Medicine.

5. Region and state readmissions progress updated with three months Medicare claims data (2016) [Measurement instrument-3 months of Medicare claims data]. Austin: TX: Quality Improvement Organization \& TMF (quality improvement network).

6. White M, Garbez R, Carroll M, Brinker E, Howie-Esquivel (2013) Is "teach-back" associated with knowledge retention and hospital readmission in hospitalized heart failure patients? 28(2). doi:10.1097/JCN.obo13e31824987bd

7. Drew CJ, Hardman ML,Hosp JL (2008) Designing and conducting research in education. Thousand Oaks, CA: Sage Publishing

8. Baxter Regional Medical Center [BRMC] rankings \& ratings. (2016) US news. [Cardiology \& Heart Surgery Scorecard]. Retrieved from www.health.usnews.com/best-hospitals/area/ ar/baxter-regional-medical-center-6710482/cardiology-andheart-surgery

9. Agency for Healthcare Research \& Quality [AHRQ]. (2017). Red-yellow-green congestive heart failure (CHF) tool. Retrieved from http://innovations.ahrq.gov/qualitytools/red-yellow $\neg-$ green-congestive-heart-failure-chf-tool

10. Moran K, Burson R, Conrad D (2014) The Doctor of Nursing practice scholarly project. Burlington, MA: Jones and Bartlett Learning.

11. White KM, Dudley-Brown S (2012) Translation of evidence into nursing and health care practice. New York, NY: Springer Jones \& Bartlett Learning.

12. Scoville R, Little K (2014) Comparing lean and quality improvement. IHI White Paper, Cambridge, MA, Institute for Healthcare Improvement.

13. Langley GJ, Nolan KM, Nolan TW, Norman CL, Provost LP (2009) The Improvement Guide: A Practical Approach to Enhancing Organizational Performance, San Francisco, CA, Jossey-Bass.

14. Minnesota Department of Health [MDH]. PDSA: Plan-dostudy-act. [Quality Improvement plan]. Retrieved from http:// www.health.state.mn.us/divs/opi/docs/qiplan.pdf.

15. Albert NM, Barnason S, Deswal A, Hernandez A, Kociol, R, et al. (2015) Transitions of care in heart failure: A scientific statement from the American Heart Association. Circulation. Heart Failure 8: 384-409.

16. Annenna C, Luttrik ML, Jaarsma T (2009) Reasons for readmission in heart failure: Perspective of patients, caregivers, cardiologists and heart failure nurse. Heart and Lung 38: $427-$ 34.doi: 101016/jhrting.2008.12.002.Epub2009

17. Ballard DJ, Ogola E, Fleming NS, Stauffer BD, Leonard BM, et al. (2010) Impact of a standardized heart failure order set on mortality, readmission, and quality and costs of care. International Journal for Quality in Health Care: Journal of the International Society for Quality in Health Care 22: 437-444.

18. Baxter Regional Medical Center (BRMC). (2014) BRMC community paramedic program receives grant. RMC Community Paramedic Mobile. Retrieved at http://www.baxterregional.org/ news_updates_view? $\mathrm{id}=212-7.9 \mathrm{~kb}$
19. Boutwell AE, Johnson MB, Rutherford P, Watson SR, Vecchioni $\mathrm{N}$, et al. (2011) An early look at a four-state initiative to reduce avoidable hospital readmissions. Health Affairs 30: 1272-1280.

20. Bindman AB, Blum JD, Kronick R (2013) Medicare's transitional care payment - A step toward the medical home. The New England Journal of Medicine 368:692-694. doi: 10.1056/NEJMp1214122

21. Bradley EH, Curry L, Horwitz LI, Sipsma H, Thompson J W, et al. (2012) Contemporary evidence about hospital strategies for reducing 30-day readmissions: A national study. Journal of the American College of Cardiology 60: 607-614. Retrieved from http://doi.org/10.1016/j.jacc.2012.03.067

22. Center for Disease Control. [CDC]. (2016a). Death: Final data for 2014. Retrieved from https://www.cdc.gov/nchs/data/nvsr/ nvsr65/nvsr65.04.pdf

23. Center for Disease Control. (CDC). (2016b). National center for health statistics. Retrieved from https://www.cdc.gov/nchs/ data/hus/hus16.pdf\#019

24. Center for Disease Control. (CDC). (2017). Heart failure fact sheet. Retrieved from https://www.cdc.gov/dhdsp/data statistics/fact sheets/fs_heart_failure.htm

25. Centers for Medicare and Medicaid Services (CMS). (2017a). Transition of care management. Retrieved from https:// www.cms.gov/Outreach-and-Education/Medicare-LearningNetwork-MLN/MLNProducts/Downloads/Transitional-CareManagement-Services-Fact-Sheet-ICN908628.pdf

26. Centers for Medicare and Medicaid Services (CMS). (2017b). Community-based care transition program (CCTP). Retrieved from http://innovation.cms.gov/initiatives/CCTP/

27. David D, Britting L, Dalton J (2015) Cardiac acute care nurse practitioner and 30-day readmission. Journal of Cardiovascular Nursing 30: 248-255. doi:10.1097/JCN.00000000000001

28. Gardner R, Qijuan L, Baier RR, Butterfield K, Coleman E A, et al. (2014) Is implementation of the care transitions associated with cost avoidance after hospital discharge? Journal of General Internal Medicine. doi: 10.1007/s11606-014-2814-0

29. Graves BA, Ford CD, Mooney KD (2013) Tele-health technologies for heart failure disease management in rural areas: An Integrative. Online Journal of Rural Nursing \& Health Care 13: 56-83.

30. Hall MJ, Shaleah L,DeFrances CJ (2012) Hospitalization for congestive heart failure: United States, 2000-2010. U.S. Department of Health and Human Services. Centers for Disease Control and Prevention. NCHS Data Brief, No. 108.

31. Hanson LO, Greenwald JL, Budnitz TB, Howell E, Halasyamani L, et al. (2013) Project BOOST: Effectiveness of a multihospital effort to reduce rehospitalization model: better outcomes for older adults through safe transitions (BOOST). doi:10.1002/ jhm.2054

32. Hickey JV, Brosnan CA (2017) Evaluation of health care quality for Doctor of Nursing practice [DNPs] $\left(2^{\text {nd }}\right.$ ed.) New York, NY: Springer Publishing

33. Hospital Compare. (n.d.). Medicare.gov. Retrieved from https:// www.medicare.gov/hospitalcompare/About/What-is-HOS.html

34. Iowa Healthcare Collaborative (2013) Teach-back basics toolkit. Retrieved from http:www.ihconline.org/aspx/general/page. aspx?pid=107

35. Institute for Healthcare \& Improvement [IHI]. (2017). Worksheet for documentation in a quality improvement plan. Retrieved from http://www.ihi.org/resources/Pages/Tools/ PlanDoStudyActWorksheet.aspx 
36. Institute of Medicine (IOM). (2011). The future of nursing: Leading change, advancing health. Washington, DC: The National Academies Press. Retrieved from http://www.the future ofnursing.org/IOM-Report National Academies of Sciences, Engineering, and Medicine

37. Jack BW, Chetty VK, Anthony D, Greenwald JL, Sanchez GM, et al. (2009) A reengineered hospital discharge program to decrease rehospitalization: A randomized trail model: Project Red. doi: 10.7326/0003-4819-150-3-200902030-00007

38. Klersy C, De Silvestri A, Gabuth G, Raisaro A, Curti M, et al. (2011) Economic impact of remote patient monitoring: an integrated economic model derived from a meta-analysis of randomized controlled trials in heart failure. Euro J Heart Failure 13: 450-459. doi: 10.1093/eurjhf/htq232.Epub 2010. Dec29.

39. Kotter International (2017) 8-steps-process-for-leading-change. Retrieved from https:/www.kotterinternational.com/8-stepsprocess-for-leading-change/

40. Kripalani S, Bengtzen R, Henderson LE, Jacobson TA (2008) Clinical research in low-literacy populations: Using teachback to assess comprehension of informed consent and privacy information. IRB: Ethics and Human Research 30: 13-19.

41. Larson EW, Gray CF (2011) Project management: The managerial process. ( $5^{\text {th }}$ ed.). Boston, MA: Irwin McGraw-Hill.

42. Lewis BJ (2017) BRMC first to receive community paramedic license in state. The Baxter Bulletin. Retrieved at http://www. baxterbullentin.com/story/news/local/2017/02/20/brmc-firstto-receive-community-paramedic-license-in-state/980747521

43. McEwen M, Wills EM (2007) Theoretical basis for nursing. ( $2^{\text {nd }}$ ed.). Philadelphia, PA: Lippincott Williams \& Wilkins.

44. Moore C, McGinn T, Halm E (2007) Tying up loose ends: Discharging patients with unresolved medical issues. Archives of Internal Medicine 167: 1305-1311.

45. Novitas (2017) Physician fee schedule. Retrieved at http:// www.novitas-solutions.com/webcenter/portal/FeeSchedules $\mathrm{JH} /$ page 197?_afrLoop=94418753926678\&_adf.ctr1state $=$ ickf58t7w_4\#!
46. Nurse Practitioner Core Competencies (2012) The national organization of nurse practitioner faculties [NONPF]. Retrieved from https:/www.pncb.org/sites/default/files/2017-02/NONPF Core_Competencies.pdf

47. Office for Human Research Protections (2017) HHS.gov. Basic HHS policy for protection of human research subjects. Retrieved from http://www.hhs.gov/ohrp/regulations-andpolicy/regulations/45-cfr-46/index.html\#46.101

48. Orem DE (1991) Nursing: Concepts of practice (4th ed.). St. Louis, MO: C. V. Mosby.

49. Rau J (2014) A guide to Medicare's readmissions penalties and data. Kaiser Health News [KHN]. Retrieved from www.khn. org/news/a-guide-to-medicare-readmissions-penalties-and-data/

50. Rizzo E (2013) Six stats on the cost of readmission for CMStracked conditions. Becker's Infection control\& Clinical Quality. Retrieved from www.beckershopialreview.com/quality/6-statson-the-cost-of-readmission-for-cms-tracked-conditions.html

51. Rodak S (2013) 20 Statistics on hospital readmissions. Becker's infection control and clinical quality. Retrieved from www. beckershospital review.com/quality/20-statistics-on-hospitalreadmissions.html

52. Roy CL, Poon EG, Karson AS, Ladak-Merchant Z, Johnson RE, et al. (2005) Patient safety concerns arising from test results that return after hospital discharge. Annals of Internal Medicine 143: 121-128.

53. Rutherford P, Nielsen GA, Taylor J, Bradke P, Coleman E (2013) How-to guide: Improving transitions from the hospital to community setting to reduce avoidable rehospitalizations. Institute for Healthcare Improvement [IHI]; Cambridge, MA: Retrieved from www.ihi.org

54. The Institute for Healthcare Improvement [IHI] triple aim (2017) The IHI triple aim. Retrieved at www.ihi.org/Engage/ Initiatives/TripleAim/pages/default.aspx University of Arkansas Medical Sciences. (UAMS). (n.d.). Arkansas tele-medicine law. Retrieved at http://arkansaselink.com/arkansas-telemedicinelaw-arkansas-act-887/.
Copyright: (02018 Kelli Camp. This is an open-access article distributed under the terms of the Creative Commons Attribution License, which permits unrestricted use, distribution, and reproduction in any medium, provided the original author and source are credited. 